\title{
Exploring exposure risk and safe management of container-based sanitation systems: a case study from Kenya
}

\author{
Eve Mackinnon, Luiza C. Campos, Niteen Sawant, \\ Lena Ciric, Priti Parikh, and Kate Bohnert
}

\begin{abstract}
Little has been studied about the potential risks and hazards arising from the use and operation of container-based sanitation (CBS) systems. Building on existing risk assessment frameworks, this case study aimed to identify exposure risks from faecal pathogens and relevant control measures in a CBS service chain. The case study employed a mixed-methods approach that included environmental sampling, key informant interviews, and direct observation. This inclusion of a behavioural dimension reflects a socio-cultural approach to risk analysis that is less evident in overtly quantitative approaches to risk assessment that are typical of the health risk field. Data from this case study was collected in Naivasha, Kenya in July 2016. The hazard intensity and role of specific transmission routes was validated by environmental sampling, which found a high level of faecal contamination on toilet surfaces and a consequent high risk of hand-to-mouth infection for users and operators. The hazard analysis identified nine critical control points where exposure risks may be either prevented or reduced via the implementation of relevant control measures. We discovered that the production of exposure risks was related to multiple, inter-related causal mechanisms and risk factors, findings we expect will guide approaches to exposure risk management in the future.
\end{abstract}

Keywords: container-based sanitation, environmental contamination, exposure risk, control measures, risk assessment

A LARGE INCREASE IN ACCESS to, and provision of, current sanitation services is required to achieve universal sanitation by 2030 and meet Sustainable Development Goal (SDG) 6 (Rochelle-Newall et al., 2015). The most recent data available highlights that 5.3 billion people globally lack access to 'safely managed' sanitation, defined as the isolation of harmful faecal pathogens in faeces and urine from human contact via safe containment and appropriate treatment of faecal matter (WHO, 2017). Given the trends of urbanization, it is increasingly acknowledged that centralized sewered infrastructure, which is highly resource intensive in terms of capital and land, is unlikely to be able to respond to growing sanitation needs, especially in urban

Eve Mackinnon (eve.mackinnon.15 @ucl.ac.uk) is a PhD researcher, and Luiza C. Campos (I.campos@ucl.ac.uk),Lena Ciric (I.ciric@ucl.ac.uk), and Priti Parikh are senior lecturers in the department of Civil, Environmental and Geomatic Engineering, University College London; Niteen Sawant is a risk assessor at Unilever Safety and Environmental Assurance Centre (SEAC), Sharnbrook, UK; Kate Bohnert is Business Development Lead at Sanivation, Naivasha, Kenya (C) Practical Action Publishing, 2018, www.practicalactionpublishing.org, ISSN: 0262-8104/1756-3488 
and peri-urban contexts (WSUP/EY, 2017). A promising response to these issues is container-based sanitation (CBS) systems, which involve the containment of waste in sealable, removable containers and the collection and conveyance of urine and faeces from multiple households to undergo treatment at a waste processing site (Tilmans et al., 2016). Importantly, CBS represents an entire value chain for faecal waste management that is independent of sewered infrastructure. Key sanitation service providers using CBS systems include Sanivation, SOIL, Sanergy, and Clean Team (Thomas et al., 2018; O'Keefe et al., 2015; Nyoka et al., 2017).

However, as the SDG 6 recognizes, increasing access to sanitation will only bring intended health benefits if sanitation is also 'safely managed'. Conditions associated with unsafe sanitation lead to the release and transmission of harmful faecal pathogens into the environment, subsequent human exposure, and possible infection (Brown et al., 2015; Prüss-üstün et al., 2004; Bain et al., 2014). Exposure to faecal pathogens is a significant public health burden associated with acute and chronic conditions such as diarrhoeal diseases, environmental enteropathy (Humphrey, 2009), stunting (Mwase et al., 2016), and poor childhood development (Ngure et al., 2014). Indeed, both on-site and off-site sanitation systems offer benefits and potential risks in regards to technology, disease prevalence, and the health status of families using the toilet (Peasey, 2000; Buckley et al., 2008). Recent studies have linked dirty toilets to increased exposure and higher rates of moderate to severe diarrhoea (Baker et al., 2016), while numerous studies more broadly demonstrate that poorly managed sanitation systems can lead to exposure to faecal pathogens and subsequent negative health impacts (Prüss-üstün et al., 2004; Katukiza et al., 2014; Drechsel et al., 2008; Buckley et al., 2008).

Presently, there is limited evidence of exposure risks specific to the operation and management of CBS systems given the infancy of these sanitation solutions. One case-control study found no strong relationship between contamination of household drinking water and CBS use (Russel et al., 2015). Another study described exposure risks arising from the use and operation of urine diversion dry toilets (UDDT), but these results were exclusively validated by literature review as opposed to empirical findings (Stenström et al., 2011). Our study is timely in relation to recent findings that sanitation workers are often inadequately protected and face increased exposure risks due to a perception of low status in society (Burgess, 2016). Furthermore, informal waste management in low income settings is linked with microbiological exposure risks and related ill-health according to a number of studies (Maricou et al., 1998; Rongo et al., 2004; Bleck and Wettberg, 2012). In higher income settings, exposure via inhalation of bio-aerosols leading to respiratory tract infections in workers in wastewater and waste management occupations, such as composting operations, is described (Carrington, 2001; Mnkeni et al., 2008; Turner et al., 2005; Walser et al., 2015). The management of operator vulnerability is typically framed in terms of compliance with control measures, such as the provision and use of protective equipment and relevant training (Medland et al., 2015).

Risk assessment approaches in engineering traditionally involve linear and simple causal mechanisms whereby accidents arise from technical failures or measurable 
hazards (Leveson, 2011). In contrast, Emch (1999) describes exposure to faecal pathogens and disease risk resulting from a 'dynamic complex of variables that exist in time and space' (Emch, 1999). This is typified in a socio-behavioural analysis of risk which places significance on both human agency and the structural contexts in which that behaviour is embedded and how it affects the way people perceive and respond to health risks (Curtis et al., 2011). Scammel (2010) states that such integration is essential to, 'improve understanding of complex exposure pathways, including the influence of social factors on environmental health, and health outcomes' (Scammel 2010: 1152). These various determinants are classified by Mayer (1986) into a set of behavioural, environmental, socio-economic, biological, and cultural components (Mayer, 1986). How risk management frameworks account for the complexity of exposure risk and ensure effective risk management, are important questions. For example, ensuring compliance to control measures is principally a behavioural outcome, that will require the integration of a number of tools and methodological approaches, including an analysis of behavioural determinants, to ensure that desired outcomes are achieved (Devine and Devine, 2009; Mosler, 2012a; Michie et al., 2014).

Existing risk management frameworks to deliver safely managed sanitation, via strategies for the prevention, reduction, and mitigation of exposure, are being steadily adopted by the sanitation industry. Sanitation Safety Plans (SSPs) provide practical guidance for qualitative exposure assessments and are designed to mitigate health risks to system operators at the site level from exposure to harmful microorganisms in faecal matter (WHO, 2016). SSPs may use a Participatory Rapid Sanitation System Risk Assessment (PRSSRA) approach in which local stakeholder knowledge informs exposure risks assessment (Campos et al., 2015). Hazard Analysis and Critical Control Points (HACCPs) is a risk framework used in food safety analysis which has been adopted by water and sanitation risk assessments to specify control measures at critical control points (CCPs) where it is possible to reduce, prevent or mitigate exposure (Edmunds et al., 2016; Westrell, 2004). Alternatively, quantitative microbial risk assessment (QMRA) may be used to identify singular and dominant exposure routes (Wang et al., 2017; Robb et al., 2017); however, this approach is resource-intensive and potentially beyond the means of small-to-medium-sized enterprises.

A CBS case study in Kenya was selected as an opportunity for a holistic exploration and validation of a conceptual understanding of exposure risk in CBS systems. We define exposure risk in CBS in terms of health consequences, understanding it to be a product of interactions between the hazard (faecal pathogens), hazardous events, transmission pathways, and the susceptibility of the receptor (Figure 1). Management of risk includes the prevention, reduction, and mitigation of exposure risk. In this case study, the risk analysis is intended to integrate both human and technical dimensions to account for their effect on the frequency and intensity of the hazard level, exposure pathways, and receptor linkages illustrated in Figure 1 (Broomfield et al., 2010; Campos et al., 2015; Stenström et al., 2011). The approach to risk assessment is informed by the different approaches and conceptualizations of risk management identified in the frameworks. 


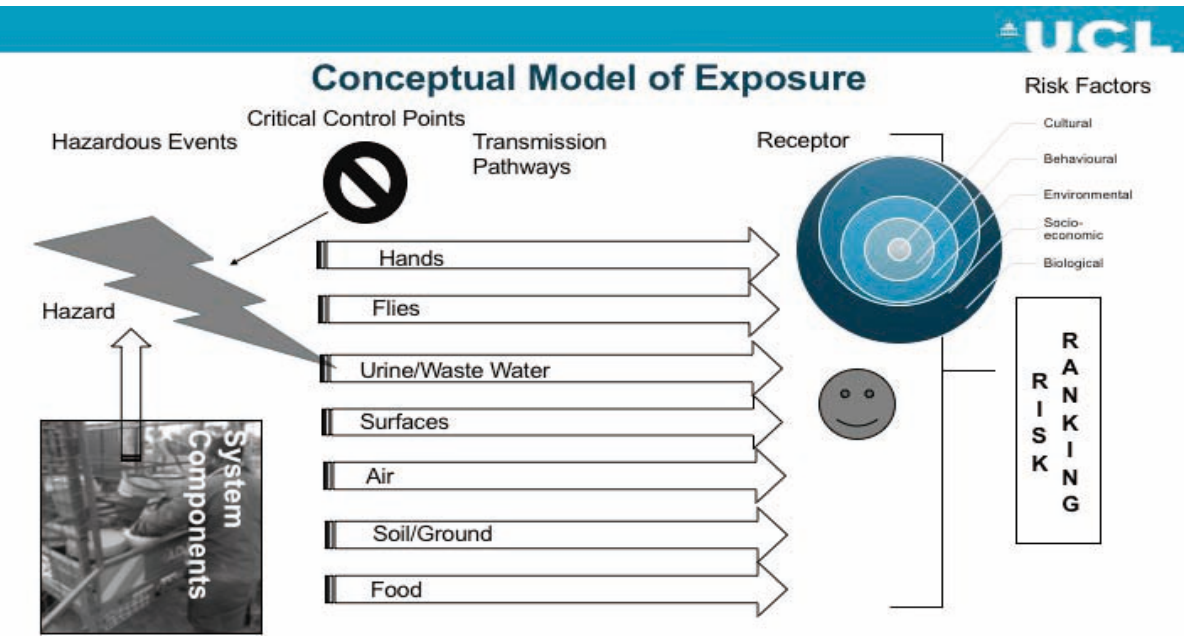

Figure 1 Conceptual model of exposure risk in CBS system illustrating the relationship between hazardous events, transmission pathways, and receptor exposure

\section{Objectives}

The overall objective of the study is to provide relevant insights of exposure risk and appropriate measures to achieve safely managed sanitation in the case study. We aim to highlight the types of contextual and behavioural factors that shape exposure risk and contribute to exposure risk management frameworks. The case study intends to contribute to robust exposure risk assessment in CBS systems through the development of methodological tools specifically highlighting the adoption of CCPs and SSPs.

\section{Study area}

We used a case study on Sanivation, a sanitation social enterprise, to characterize exposure risks in a specific CBS system. Sanivation provides a CBS service to approximately 100 customers in which they collect, treat, and transform the faecal waste into a solid fuel (Berner et al., 2015). Operations are located in a peri-urban settlement with approximately 60,000 inhabitants outside of Naivasha, Kenya. The study period took place from 10 July to 2 August 2016.

\section{Ethics}

Ethics approval was granted by the Chair of the UCL Research Ethics Committee at University College London (9097/001, approved 7 June 2016). Sanivation granted approval to carry out research work (granted 12 May 2016) according to the research protocol and worked closely with the researcher to ensure the research was carried out in a rigorous and methodical manner. 


\section{Methodology}

The methodological approach allowed for an exploration of risks which explicitly considered human behaviour in understanding pathways of diarrhoeal diseases; seen as an important risk factor in transmission of diarrhoeal diseases (Antwi-Agyei et al., 2016; Darout et al., 2005; Graf et al., 2008). Therefore, including socio-behavioural analysis was key to understanding and describing exposure risks during CBS operations, in particular how individuals perceive and respond to health hazards. We used a mixed-methodological approach to incorporate both qualitative and quantitative analyses to develop an understanding of: the level of environmental contamination (severity); principal exposure risks identified in system components (exposure risk outcomes); and the risk factors influencing relationships leading to these exposure risks (risk factors and transmission pathways).

The case study utilized four main data collection components: 1) environmental sampling (severity); 2) hazard analysis (exposure risk outcomes); 3) a visual risk household survey $(\mathrm{n}=20)$ (risk factors and transmission pathways); and 4) key informant interviews $(n=6)$ (risk factors and transmission pathways).

The first component, environmental sampling, captured information on the level of faecal contamination of household toilet fomites (inanimate contact surfaces). We tested the samples for the presence of Escherichia coli (E. coli), a faecal indicator bacteria (FIB). From a total of 52 households involved in the study, we selected 11 different households using random number sampling methodology. In addition, we sampled 34 faecal collection container surfaces and 15 urine collection container surfaces at the waste transfer site using the same selection methodology. We swabbed each fomite using a representative $10 \mathrm{~cm}^{2}$ area, stored the swabs in a $15 \mathrm{ml}$ vial with $7 \mathrm{ml}$ of PBS solution, and quickly transported them back to the laboratory in a cool box. We processed the samples using the standard IDEXX Colilert Protocol to provide a most probable number (MPN) of faecal coliforms with lower and upper detection limits of 1 and 2,400 MPN/100 millilitres, respectively. If no fluorescence was visible in the tray, then a zero value was assigned. We assumed the value of the upper detection limit if all the cells in the tray were fluorescent (Russel et al., 2015). We calculated the colony forming units (CFU) E. coli/100 $\mathrm{cm}^{2}$ using a formula that accounts for sampling efficiency of the swab and dilution factor. Statistical analysis of the colony counts was performed to obtain average, median, and standard deviation. The E. coli data was log-transformed (log 10), whereby zero colony counts were exchanged with a value of 1.0 (Devamani et al., 2014) so zero value could be analysed representing <1 CFU (du Preez et al., 2011). The 'human faecal equivalents' methodology developed by Julian (2016) makes it possible to link the level of environmental contamination found on fomites to the possible infection risk (Julian, 2016). We followed the first step of this methodology and approximated the level of environmental faecal contamination by dividing the E. coli concentrations on reservoirs by the average reported E. coli concentration in faeces, which was estimated conservatively as $10^{6} \mathrm{CFU} \mathrm{g}^{-1}$ (Forsythe, 2010; Mara and Oragui, 1985). It bears noting that the swabbing technique for microbiological analysis has limitations affecting sampling, namely, swabbing does not necessarily recover all of the 
bacteria from a surface and recovered bacteria may not be released from the swab (Moore and Griffith, 2007). Despite these constraints, we employed the swabbing technique because alternative methods for microbiological analysis were costprohibitive. To obtain data as robust as possible, we conducted a triplicate sampling procedure on both wood and plastic surfaces to explore any significant differences in the sample efficiency. This was included in interpretation of results as a factor of swabbing efficiency based on laboratory experiments. The test protocol followed established protocols (Moore and Griffith, 2007; PHE, 2013).

The second data collection component was a hazard analysis involving: 1) system mapping of activities undertaken along the entire service chain (capture, containment, collection, transport, treatment, and safe reuse or disposal) including volumes and types of waste; and 2) identification of hazardous events and control measures, adapted from relevant modules of the SSP manual. The definition of a hazardous event, was 'an event which might lead to human contact (users, operators or communities) with faecal waste and provide an opportunity for transmission and infection' (WHO, 2016). Utilizing this definition as guidance, we developed a risk matrix that measured on one axis the frequency with which hazardous events might occur based on the presence (or absence) of appropriate control measures and the potential consequences or severity of health impacts on another.

A preliminary workshop with the directors and project managers of CBS organizations (Oxford Toilet Summit Participants, personal communication) informed our initial system mapping of the CBS system. For the case study we limited our assessment system boundary to the first four CBS components: containment during toilet use, emptying and collection, transport, and waste processing and treatment of the excreta and urine. For simplification, we did not consider reuse of the final product in the system mapping and subsequent exposure assessment. We shadowed the collection operator over four collection cycles (around 20 households/collection cycle) to observe activities and exposure events occurring at both the user interface and during collection and conveyance. Similarly, we observed activities over a two-day period in the treatment and processing site. Table 1 illustrates the format of a structured observation checklist which was employed to note the potential hazardous events observed during this observation period. We then performed a risk analysis in which we characterized the exposure risk associated with a given hazardous event as high, medium or low. Finally, we utilized Codex guidelines (WHO, 2003) to aid us in determining

Table 1 Hazard analysis worksheet used for observation of hazardous events in second data collection component

\begin{tabular}{|c|c|c|c|c|c|c|c|}
\hline Hazard & $\begin{array}{l}\text { Exposure } \\
\text { source }\end{array}$ & $\begin{array}{l}\text { Type of } \\
\text { hazardous } \\
\text { event }\end{array}$ & $\begin{array}{l}\text { Exposure } \\
\text { pathway }\end{array}$ & $\begin{array}{l}\text { Controls/ } \\
\text { mitigation }\end{array}$ & $\begin{array}{l}\text { Who is } \\
\text { at risk? }\end{array}$ & $\begin{array}{l}\text { Likelihood or } \\
\text { Frequency of } \\
\text { hazard } \\
\text { \# events/day }\end{array}$ & $\begin{array}{l}\text { Severity } \\
\text { of hazard } \\
\text { in terms } \\
\text { of health } \\
\text { impact }\end{array}$ \\
\hline
\end{tabular}

Source: adapted from Codex Alimentarius guidelines 
points where hazardous events can be controlled or minimized, referred to as Critical Control Points (CCPs). Because the implementation of control measures and establishment of monitoring protocols fell outside the scope of the project objectives, we did not design a system for setting critical limits or monitoring and verifying control measures.

The third data collection component consisted of a structured household survey ( $n=20$ ) of closed-ended questions and observations, administered house-to-house, which took place during the observation of the collection events. The survey sheet is attached in Annex 1. We designed the survey to identify the likelihood of potential transmission routes of faecal oral pathogens via hands, soil, or vectorrelated transmission routes and used predetermined risk factors and indicators drawn from relevant literature. Risk factors and indicators included the type of anal cleansing materials used (McMahon et al., 2011), the functionality and accessibility of handwashing devices (Baker et al., 2016), the status of toilet cleanliness (Moore and Griffith, 2007), odour, the presence of flies, spillages around the toilet, and the type of flooring (Pickering et al., 2012; Worrell et al., 2016; Robb et al., 2017). We performed analysis of the survey using Microsoft Excel to identify averages, means, and percentages of exposure risk and triangulated those results with data collected during the hazard analysis.

The final data collection component involved stakeholder consultation, comprising six in-person key informant interviews (KIIs) and informal discussions conducted with front-line staff and users over the course of several days. Informants were briefed prior to the interview with an explanation of the research objectives and were shown Figure 1 to describe the routes of transmission of faecal pathogens relevant to CBS systems. The discussion framework was structured to elucidate personal perceptions of health risks to themselves and others. This included perceived susceptibility and severity to health risks as well as perceived barriers or ability to prevent exposure to risks (Ajzen, 1985; Mosler, 2012b). The interviews provide rich narratives about risk perceptions, individual behaviours, and faecal exposure during the use and operation of CBS sanitation infrastructure, which support a deeper understanding of the observational and quantitative data informing hazardous events and exposure pathways, triangulated with survey observations. We recorded interviews on a smartphone using Voice Recorder software by TapMedia Ltd. We then transcribed the interviews in Nvivo and coded them using simple descriptive codes to identify major themes within the text.

\section{Results}

\section{Environmental contamination}

In order to collect information on the level of contamination at CBS sites, we sampled a total of 24 household toilet fomites (seat and surfaces) and 48 collection containers (faecal and urine) for the presence of E. coli on the exterior contact surface. Overall, 41 per cent of household toilet fomites sampled had a positive presence of $E$. coli, while 80 per cent of collection containers were free from $E$. coli. 


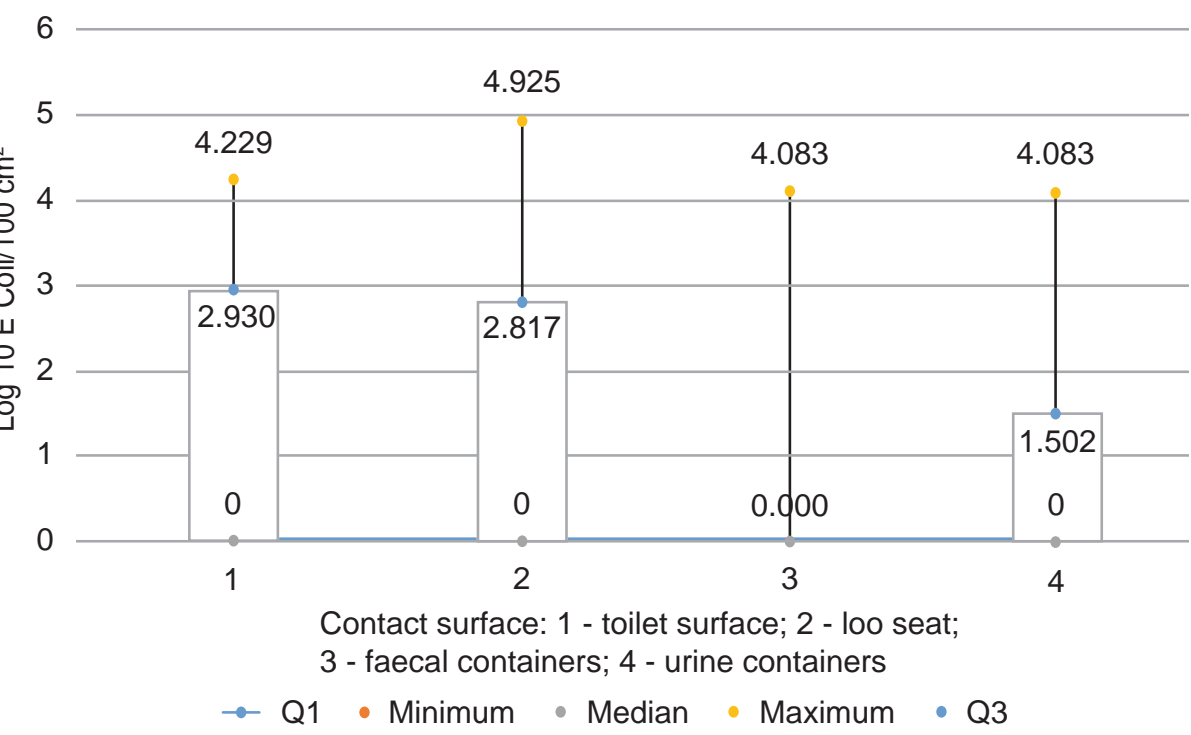

Figure $2 \mathrm{E}$. coli concentrations at point of surface contact on toilet surfaces

Note: The lines of the box-and-whisker plot represent, from the bottom: the minimum value, the lower quartile, the median value, the upper quartile and the maximum value. The difference between the upper and lower quartile (between the outer lines of the box) represents the Interquartile Range (Exley et al., 2015).

The distribution of the environmental data is presented in Figure 2. The data indicates the variability of the concentrations of $E$. coli on contact surfaces (large inter-quartile ranges). For all contact surfaces (1-4) the lower value and lower quartile are the same as the data is highly positively skewed to the left indicating surfaces are free from E. coli. For faecal containers there is no inter-quartile range as there was such a high proportion ( $>75$ per cent) of zero values after transformation.

Table 2 presents the log transformed mean concentrations of E. coli on contact surfaces. The maximum mean value was determined to be on the loo seat

Table 2 Transformed log data of E. coli concentrations found on different contact surfaces along the sanitation value chain

\begin{tabular}{lccccc}
\hline Contact surfaces & \multicolumn{5}{c}{$\begin{array}{c}\text { Log transformed E. coli data adjusted for sampling efficiency } \\
\left.\text { (log } 10 \text { E. coli/100 } \mathrm{cm}^{2}\right)\end{array}$} \\
\cline { 2 - 6 } & Mean & Median & Maximum & Minimum & $\begin{array}{c}\text { Standard } \\
\text { deviation }\end{array}$ \\
\hline Surfaces of the toilet & 1.26 & 0 & 3.73 & 0 & 1.79 \\
Loo seat & 1.39 & 0 & 4.93 & 0 & 1.95 \\
Urine containers & 1.16 & 0 & 4.08 & 0 & 1.63 \\
Faecal containers & 0.40 & 0 & 3.81 & 0 & 0.97 \\
\hline
\end{tabular}

Note: The mean values compare the values of $\log 10 \mathrm{E}$. coli CFU/100 $\mathrm{cm}^{2}$ for toilet surfaces $(n=13)$, loo seats $(n=11)$, urine collection containers $(n=15)$, and faecal collection containers $(n=34)$. 
Table 3 Approximate amount of faecal contamination observed on toilet surfaces frequently handled during servicing activities in CBS.

\begin{tabular}{lcc}
\hline Contact surfaces & \multicolumn{1}{c}{ Human faeces equivalent grams $E$. coli $/ 100 \mathrm{~cm}^{2}$} \\
\cline { 2 - 3 } & Mean & Maximum \\
\hline External sides of blue box & $0.0023\left(2 \times 10^{-3}\right)$ & $0.016\left(10^{-2}\right)$ \\
Loo seat & $0.0104\left(10^{-2}\right)$ & $0.842\left(8 \times 10^{-1}\right)$ \\
Urine containers & $0.0015\left(10^{-3}\right)$ & $0.012\left(10^{-2}\right)$ \\
Faecal containers & $0.0003\left(3 \times 10^{-4}\right)$ & $0.012\left(10^{-2}\right)$ \\
\hline
\end{tabular}

Note: Comparison of the mean and maximum amounts of faecal contamination across the sampled surfaces: toilet surfaces $(n=13)$, loo seats $(n=11)$, urine collection containers $(n=15)$, and faecal collection containers $(n=34)$.

(1.39 $\log E$. coli/100 $\left.\mathrm{cm}^{2}\right)$ followed by the surfaces of the toilet $(1.26 \mathrm{log}$ E. coli $/ 100 \mathrm{~cm}^{2}$ ). Samples from the urine and faecal collection container surfaces were somewhat lower, at 1.16 and $0.4 \log$ E. coli $/ 100 \mathrm{~cm}^{2}$, respectively (Table 2), although comparable maximum levels of $E$. coli concentration were observed across all fomites sampled from 4.083 to $4.925 \log$ E. coli/100 $\mathrm{cm}^{2}$.

Table 3 presents the estimated amount of faecal equivalent on the key contact surfaces. The highest amount of mean faecal contamination was on loo seats $\left(10^{-2} \mathrm{~g}^{-1}\right.$ faeces) and lowest values observed were on faecal collection containers $\left(10^{-4} \mathrm{~g}^{-1}\right.$ faeces). The maximum amount of faecal contamination observed was also on loo seats (approximated at $10^{-1} \mathrm{~g}^{-1}$ faeces).

\section{Hazard analysis: exposure risk}

The hazard analysis revealed multiple hazardous events and opportunities for exposure related to toilet use, emptying and collection, transport, and waste processing and treatment illustrated in Table 4. We present the findings of the hazard analysis below for each of the system components and cross-reference them with multiple data elements.

Table 4 Summary of hazard analysis according to SSP guidelines and the CCPs identified in the case study

\begin{tabular}{lll}
\hline $\begin{array}{l}\text { Potential hazardous events } \\
\text { by critical control point }\end{array}$ & $\begin{array}{l}\text { Risk } \\
\text { level }\end{array}$ & $\begin{array}{l}\text { Risk management } \\
\text { recommendations }\end{array}$ \\
\hline $\begin{array}{l}\text { 1. Toilet use } \\
\begin{array}{l}\text { Cross-contamination/blockages of } \\
\text { urine diversion through misuse or } \\
\text { diarrhoeal events }\end{array}\end{array}$ & $\begin{array}{l}\text { High } \\
\text { (especially }<5 \\
\text { or elderly) }\end{array}$ & $\begin{array}{l}\text { Training and awareness raising } \\
\text { Appropriate toilet design }\end{array}$ \\
$\begin{array}{l}\text { Airborne particulates from poor } \\
\text { sealing of collection containers } \\
\text { leading to ingestion and inhalation }\end{array}$ & Low for users & $\begin{array}{l}\text { Strong sealing mechanism } \\
\text { (lid/cap/bag fastening) for waste } \\
\text { collection containers }\end{array}$ \\
$\begin{array}{l}\text { Spillages or overflow from collection } \\
\text { container (especially urine, faeces, } \\
\text { tissue) contaminates surfaces }\end{array}$ & Low & $\begin{array}{l}100 \% \text { of collection containers sealed } \\
\text { and leak-proof to prevent spillages }\end{array}$ \\
\hline
\end{tabular}




\begin{tabular}{lll}
\hline $\begin{array}{l}\text { Potential hazardous events } \\
\text { by critical control point }\end{array}$ & $\begin{array}{l}\text { Risk } \\
\text { level }\end{array}$ & $\begin{array}{l}\text { Risk management } \\
\text { recommendations }\end{array}$ \\
\hline & Regular and frequent servicing: \\
& e.g. SMS-based collection dispatch \\
& service to efficiently plan collection \\
& and servicing schedules \\
& Use of sensors inside collection \\
& container
\end{tabular}

Signage and risk communication: communication and emergency number clearly positioned for response in case of spillage

The seal should be regularly monitored for wear and tear and replaced in good time

\section{Handwashing}

Hand contamination due to failure to

Access to handwashing facilities contact with faeces due to lack of anal cleansing materials

Transfer of surface contamination of toilet surfaces onto hands

Enabling behaviour change to encourage uptake and practice of handwashing

Cleaning and disinfection protocols

\section{Cleaning toilet surfaces}

Handling enhanced surface

High for operators operator exposure

\section{Collection and emptying}

Malfunctions of PPE and noncompliance to PPE

Handling of contaminated surfaces and containers
High

Full PPE worn $100 \%$ of the time

Glove protocol: e.g. disposable latex gloves used where red gloves are not appropriate providing they are exchanged between households

Hand sanitization between households to prevent potential transfer of contamination between households on operator's gloves 
Table 4 (continued)

\begin{tabular}{|c|c|c|}
\hline $\begin{array}{l}\text { Potential hazardous events } \\
\text { by critical control point }\end{array}$ & $\begin{array}{l}\text { Risk } \\
\text { level }\end{array}$ & $\begin{array}{l}\text { Risk management } \\
\text { recommendations }\end{array}$ \\
\hline & & $\begin{array}{l}\text { Regular and frequent training to } \\
\text { communicate health risks and } \\
\text { increase perception of exposure risks } \\
\text { among operators }\end{array}$ \\
\hline Spillages of raw waste & Low & $\begin{array}{l}\text { Containers should be directly } \\
\text { placed onto the collection vehicle } \\
\text { to prevent the risk of spillages and } \\
\text { unsupervised collection containers } \\
\text { in the local environment and } \\
\text { exposure to people }\end{array}$ \\
\hline
\end{tabular}

\section{Transportation}

Spillages occurring during transport of waste is when most community exposure occurs

Exposure occurs via multiple pathways resulting from spillages during transport of waste

\section{Offloading of containers at waste treatment}

Handling of contaminated container and raw waste is a potential hazardous source to operators and the wider environment during loading and offloading

\section{Transfer of urine/excreta to storage/treatment}

Handling, aerosolization, and manipulation of the raw waste Spillages of raw waste
Medium

to high depending on road conditions

Medium for urine

Low for solids

Medium to low
Covered collection vehicle to prevent leakage and environmental contamination

At the end of shift collection vehicles should be fully washed down and disinfected with $0.2 \%$ chlorine solution while wearing PPE

An appropriate environmental spillage protocol (including disinfection with $0.5 \%$ chlorine solution)

Appropriate monitoring and management

PPE worn $100 \%$ of the time Signage and risk communication: communication and emergency number clearly positioned for response in case of spillage

Full PPE worn $100 \%$ of the time Regular and frequent training to communicate health risks and increase perception of exposure risks among operators

Signage and risk communication

Full PPE worn $100 \%$ of the time

Physical fly barrier in waste transfer zone

Spillage protocol and wash down 


Potential hazardous events Risk Risk management

by critical control point level recommendations

Regular and frequent training to communicate health risks and increase perception of exposure risks among operators

Malfunction of PPE and non-

Low

Signage and risk communication compliance

\section{Washing and disinfection}

The main hazardous source

High

Full PPE worn $100 \%$ of the time

was splashing of contaminated

wastewater onto the operator

Contamination of the environment

following discharge of the wastewater

Regular and frequent training to

communicate health risks and increase perception of exposure risks among operators

Cleaning and disinfection protocols

\section{Incineration of solid waste}

Incineration of the contaminated

Medium

Full PPE worn $100 \%$ of the time waste. Release of airborne particulates and inhalation by the operator or nearby community

Regular and frequent training to communicate health risks and increase perception of exposure risks among operators

Signage and risk communication

Toilet use. At the user level, hand contamination was the hazardous event with high exposure risks occurring through accidental contact with faecal matter or handling of contaminated surfaces and subsequent direct or indirect oral ingestion. User interviews revealed age-specific user groups (those under five and the elderly) who experienced the greatest difficulty with using the toilet, resulting in a higher likelihood of misuse and hand contamination. These findings underscore the importance of adequate supervision and training by heads of the households. For example, the following interviewee indicated, 'I have shown the children how to use it, [so] they never put their hands inside'. The household survey indicators for hand contamination also revealed poor access to cleaning materials for anal cleansing and handwashing, indicated by presence of newspaper and toilet paper for anal cleansing in refuse containers collected by Sanivation; only 50 per cent of households surveyed had access to tissue paper or newspaper (30 per cent and 20 per cent, respectively) and an even smaller proportion (20 per cent) had access to functional handwashing. Moreover, 30 per cent of toilets had visible faecal smears on their surfaces. Notably, some of the findings revealed how the cost of cleaning materials is a factor relevant to exposure through hand contamination. For example, one interviewee indicated that, '[T]issue (toilet paper) is best, but when the month is at the corner [end] we do not have money 
that time'. User interviews also suggested that even when handwashing facilities are available, individual handwashing habits are not consistently adhered to. For example, one user stated that '(B)ecause if you go to the toilet you can forget to wash your hands, it is very dangerous. You can see your friends and touch and [be]come contaminated'.

Our findings indicated that spillages and blockages of faecal matter into the urine diverting portion of the toilet, or 'cross-contamination' during toilet use, constituted a hazardous event with medium exposure risks for toilet operators, especially in cases where toilet users demonstrated poor defecation habits. We found exposure risk for toilet users from cross-contamination to be lower given that users were constrained to their own toilet facilities and the household survey indicated that 90 per cent of urine diversions were free from blockage at the time of observation. However, user interviews referred to specific aspects of toilet design that elevated the likelihood of misuse, especially for younger users. For example, the following interviewee discussed her child's difficulties with using the toilet:

(A)lso the toilet is more up, so he has to struggle, to sit on it, always he has to miss, because he poops in the urine barrel instead of - even the hole is bigger than him, but I go and clean it. He is five years.

Another interviewee indicated that 'older users ... are not able to sit adequately on the box; some might fall inside'.

We considered all other hazardous events identified during the hazard analysis to present low exposure risks. We detail these events in Table 4 and refer to the household survey and interview results.

Collection and conveyance. We found high exposure risks during collection and conveyance to toilet operators given the high frequency of their manual handling of contaminated surfaces (Table 4). Although the hazard analysis revealed that certain control measures for toilet operators were in place, including the mandatory use of personal protective equipment (PPE), including gloves and other hand hygiene protocols, compliance with those measures remained less than 100 per cent. Additionally, in the absence of strict cleaning protocols, we observed that some operators would remove their heavy-duty gloves to facilitate cleaning. Operators noted these risk outcomes in their interviews and found them to be higher for service operators than for operators working at the waste treatment site, based on a differential frequency of exposure. As one operator noted: 'The collector is the one who is more at risk with collecting the poop, who is at more reaching the households not only once or twice'.

We determined that there were low-to-medium exposure risks due to urine spillage from waste containers during collection and conveyance. Specifically, we found that spillage risk was initially attributable to overfilling and/or the poor condition of container lids and seals and then exacerbated during conveyance by the use of a collection vehicle that wasn't fully sealed and by bumpy road conditions. The existing spillage protocol, which clearly articulated steps to follow after a significant spillage, did not reduce or prevent the immediate causes of spillages 
observed, meaning the control measures were only partially effective and exposure risk observed cannot be completely removed. Aside from direct physical contact with human waste, the inhalation of bio-aerosols presented another exposure route for operators. However, this risk factor remained relatively low during the performance of collection and emptying services, given that faecal waste containers were fully covered, and the operators were observed to be wearing protective face masks during collection and emptying activities.

Waste treatment and processing. Our hazard analysis identified potential exposure risks from aspects of waste treatment and processing observed during the structured observations. Specifically, operators encountered high exposure risk from spillages during the offloading, as well as splashing during the cleaning of the waste containers, in the absence of a mechanized process or other physical design parameters that may have controlled exposure risks. The exposure risk was mitigated in part, by control measures, such as wearing PPE.

We identified all other hazardous events during waste treatment and processing as presenting low exposure risk. Our findings were supported by direct observation of operators' access to and high compliance with effective PPE measures, as well as by interviews with front-line staff who discussed how pre-employment and regular training instilled in them a keen sense of risk awareness. For example, we identified a low risk of exposure to bio-aerosols during incineration of plastic bags as operators complied with wearing PPE masks and were trained to identify insufficient waste burning temperatures through the production of a black/grey smoke and make necessary corrections. However, the risk of bio-aerosol exposure could increase in instances where an insufficient chimney height on the incinerator meant that smoke was generated at the level of the operators' heads.

Critical control points. Finally, we identified from the hazard analysis nine critical control points (CCPs) where it is possible to eliminate or reduce specific exposure to faecal pathogens resulting in possible health risks. These nine CCPs are: 1) toilet use; 2) handwashing; 3) cleaning of toilet surfaces; 4) collection and emptying of containers; 5) transportation of waste; 6) offloading of raw faecal sludge and urine; 7) the processing and transfer of waste to treatment; 8) washing and disinfection; and 9) incineration of solid waste (non-faecal). At these CCPs, we enumerated hazardous events and control measures and associated steps in Table 4, in which we also issue recommendations for new and/or improved control measures designed to reduce exposure risk.

\section{Discussion: combining findings of environmental contamination, transmission pathways, and exposure risk}

Our research aim was to characterize exposure risks to users and operators in the context of a specific CBS case study, performing a risk assessment that we triangulated with environmental sampling, a household survey, and key stakeholder interviews. Each qualitative and quantitative data stream garnered through the Sanivation case study yielded important research outputs. Cumulatively, 
we believe our findings provide a nuanced understanding of exposure risks and control measures within the context of a specific CBS case study that is not previously found in sanitation research. We suggest that, if insufficiently managed, the hazardous events we identify in our research may present exposure risks with adverse consequences to occupational and public health outcomes. We critically analysed the findings in relation to previous studies of exposure risk and disease transmission, as well as studies detailing exposure risks associated with occupational safety and health hazards in sanitation and waste management in both developing and developed country contexts (Bleck and Wettberg, 2012; Turner et al., 2005; Rongo et al., 2004).

We recognize several limitations and assumptions made in the supporting data. Firstly, the small sample sizes precluded statistically relevant analysis and the use of control groups (Tilmans et al., 2016). Extrapolating our findings to other CBS systems is hampered by the lack of confidence with which we can be sure these results are representative of this case study let alone other CBS systems. No data was collected from other onsite or offsite sanitation systems, given that it was out of the scope of the project. Note our study did not set out to compare the exposure risks in CBS systems with alternative sanitation systems; instead our objective was to highlight the exposure risks and inform effective risk management approaches relevant in the context of a particular case study. However, future research should encompass comparisons between sanitation systems to make evidence-based decisions when promoting sanitation systems to meet the SDG 6 of universal sanitation. Lastly, the researchers were not able to fully involve the specific team charged with risk assessment, which necessitated that we rely heavily on individual expert opinion when assigning risk levels. However, we argue that the detailed narratives of exposure gleaned from the household survey and interview data, as well as the variety of data streams we utilized, are factors counterbalancing the constraints in our findings.

In terms of the severity of environmental exposure, the study found the mean concentration of $E$. coli across the range of contact surfaces ranged from 0 to $1.39 \mathrm{log}$ E. coli $/ 100 \mathrm{~cm}^{2}$, while the maximum level was observed on toilet seats (4.93 log E. coli $/ 100 \mathrm{~cm}^{2}$ ). The modest levels of faecal contamination on fomites corresponded to estimated human faecal equivalents between $10^{-4}$ and $10^{-2} \mathrm{~g}^{-1}$ faeces, and a maximum amount of $10^{-1} \mathrm{~g}^{-1}$ faeces found on loo seats. The consequence in terms of infection risks to exposure is based on specific dose-response relationships (Haas, 2014) which define the dose of pathogenic cells required for an infection in an exposed individual. For example, Julian (2016) assumed an infective dose of Shigella and the number of pathogen cells shed per gram of faeces during infective periods, and proposed that a level of environmental contamination of $10^{-7} \mathrm{~g}^{-1}$ faeces represents a 'non-negligible risk of infection to exposure' (Julian, 2016). In the context of this case study, even the lowest estimation of faecal equivalents on collection containers $\left(10^{-4} \mathrm{~g}^{-1}\right.$ faeces) poses a potentially high risk of infection to exposure. Previous studies evaluating toilet use have similarly found that dirty toilets present exposure risk to toilet users and operators (Baker et al., 2016; Stenström et al., 2011; Höglund, 2001), while faecal contamination of surfaces have been linked to outbreaks of diarrhoeal diseases (Abad et al., 2001). The infection risk presented by 
surface contamination will depend on the characteristics of the specific pathogen such as, pathogen load, infectious dose required (Katukiza et al., 2014), and the environmental persistence (Julian, 2016) of the pathogen. The technical challenge and expense of defining microbial hazard to pathogen level may preclude quantitatively assessing infection risks; moreover primary data on disease aetiology in the community is often not available. Therefore, sanitary household indicators are useful to guide risk assessments where there is an absence of microbial hazard data. Secondary data such as community health surveillance may also provide guidance for risk assessment. In general, a higher risk of transmission from surfaces has been observed during the acute infection stage of diarrhoeal diseases (Barker and Bloomfield, 2000) due to higher pathogen load in faeces.

The presence of faecal smears, observed in 30 per cent of households surveyed, broadly corresponded to the 41 per cent frequency of $E$. coli contamination we found on household contact surfaces. Our study provides evidence to support the conclusion that faecal smears are a reliable indicator of surface contamination; however, the number of samples required would be far larger for this to be statistically relevant. A previous study by Scott and colleagues (1982) undertaken in the United Kingdom testing bathroom surfaces in domestic household environments suggests that the origin of surface contamination derives from faecal pathogens and found comparably high levels of faecal contamination (Scott et al., 1982). Although it is possible for faecal contamination to derive from external sources (not related to the toilet faecal matter), the UK study controlled for significant external environmental contamination, thereby establishing a precedent for a conclusion that the levels of toilet contamination encountered originated from faecal matter from the toilets themselves.

Infection risk also depends on the ability of contaminated fomites to transfer contamination to another surface, which, in turn, depends in part on the porosity of the contaminated material. Previous studies point to a high variability of transfer rates ranging from $<0.01$ per cent to 50 per cent, with the highest bacterial transfer rate corresponding to the presence of hard, non-porous surfaces (Rusin et al., 2002; Julian et al., 2010). Lingaas and Fagernes (2009) found bacterial transfer from the hands occurred more readily from gloved hands than bare hands during personto-person contact (Lingaas and Fagernes, 2009). Conversely, disinfection efficacy appears to be greater for gloved as opposed to bare hands (Scheithauer et al., 2016). This role of fomites in exposure is relevant given the role of gloves in hand hygiene and contact transmission and the potential implications for exposure in CBS systems. Overall, little research has been conducted on the efficacy and role of gloves and other hand hygiene procedures in field trials of sanitation systems. The relationship between fomites, transfer efficiency, hand contamination, and exposure risk in a case study selected to represent a CBS system is an important issue under discussion in a forthcoming paper.

Our hazard analysis, which followed SSPs guidelines, produced novel results delineating events with high, medium, and low exposure risks. Our analysis was combined with the HACCP framework to identify critical control points (CCPs) where it is possible to prevent or reduce exposure risks, thereby protecting the health and safety of toilet users, operators, and the community. We identified nine CCPs 
associated with toilet use, collection and transport, treatment and final disposal of waste materials (Table 4). We acknowledge that toilet use and handwashing (CCP 1 and 2) would likely be relevant for most sanitation systems and are not unique to this case study or CBS systems. Indeed toilet use has been associated with the positive presence of pathogens on hands (Feacham et al., 1983) and the transportation of faecal pathogens into the environment after defecation is linked to secondary contamination of foods, fomites, and water (Mattioli et al., 2013; Wang et al., 2017). The remaining seven CCPs (Table 4) are uniquely associated with the specific processes and steps associated with the cleaning, collection and emptying, transportation, treatment and disposal of human waste in this case study of a CBS system, yet we would expect CCPs to vary according to the processes and steps occurring in different CBS systems. We highlight the role of identification of CCPs in risk management, which, when combined with successful control measures, is fundamental to health and safety across the entire CBS sanitation value chain. Health risks frameworks that use CCPs are noted in the management of health risks from disposal of contaminated human waste in global contexts (Edmunds et al., 2016). This study provides a timely update to the assessment of health risks arising from urine diversion dry toilets (UDDT) performed by Stenström and colleagues (2011) which identified similar potential exposure points, equivalent to CCPs (Stenström et al., 2011).

Hand contamination presented high exposure risks for toilet users and was largely attributable to poor access to adequate anal cleansing and handwashing products, as well a failure by some toilet users to wash their hands properly 'post-defecation' when handwashing materials were available. These findings are replicated in other studies where the link between hand hygiene and diarrhoeal transmission is well proven (Baker et al., 2016; Mattioli et al., 2013, 2015; Cairncross et al., 2010; Curtis 2000). The recent SaniPath study acknowledged that hands play a pivotal role in exposure. That said, as Wang and colleagues (2017) point out, significant hand contamination does not necessarily imply high exposure given a rapid temporal variability in the hand contamination and, therefore, limited occurrence of actual ingestion (Wang et al., 2017).

Overall, we found exposure risk from airborne pathogens to be comparatively low in the presence of adequate safeguards and controls. Previous risk evaluations have presented an elevated risk of exposure from direct inhalation of viruses and bacteria due to the presence of helminth eggs on operator masks during pit emptying (Buckley et al., 2008). Airborne routes have also been deemed a significant disease transmission pathway in both the food and waste processing industries (Maricou et al., 1998; Buttner and Stetzenbach, 1993). A systematic review linked an elevated risk of respiratory diseases with composting and waste sector occupation, due to inhalation of bio-aerosols (airborne particles of biological origin), finding that immunosuppressed persons are particularly vulnerable (Walser et al., 2015). The quantification of potential health risks is precluded by a lack of data or measurements of exposure to bio-aerosols in the workplace(Walser et al., 2015). One study found good working conditions accounted for low health risks arising from exposure to bio-aerosols but warned about extrapolating the same conclusions to 
populations with less satisfactory working conditions (Tschopp et al., 2011). Such a warning may be heeded in CBS systems operating in low income countries where workplace conditions are not comparable.

The non-compliance with PPE safety protocols was a high exposure risk for collection operators, which appears to be a systemic problem across various industries and geographies. For example, safety reviews of occupational health risks have demonstrated compliance to hand hygiene protocols commonly to be as low as 40 per cent in healthcare workers and non-compliance to be linked to increased risk of gastrointestinal disease (Peasey, 2000; Stenström et al., 2011; Enger et al., 2013). In other scenarios, poor compliance with PPE protocols contributed to 30 per cent of sick leave and time off for waste operators (Haagsma et al., 2012). A key finding from our analysis of KIIs with operators in the case study was that the level of operator non-compliance varied across system components and that this outcome appears to be attributed to differences in risk perceptions affected by training, relevant risk signage, and peer-to-peer enforcement. The impact on behaviour is discussed below. We also found that compliance with PPE protocols alone was insufficient to reduce specific exposure risks to operators during some of the activities performed during waste treatment due to limitations of existing PPE equipment. The physical characteristics of the workflow, specifically, the intensity and frequency with which operators manually handle waste, may augment exposure risks faced by CBS system operators during collection and treatment activities. We found that manual activities such as turning of plastic bags inside out to evacuate faeces and emptying of multiple small volume urine containers is highly intensive and repetitive. The level of individual exposure risk resulting from repetitive activities is cumulative as opposed to a single one-off event. This finding is reported in risk analyses of industries similarly characterized by a predominance of manual handling of municipal waste in contexts similar to the study area (Bleck and Wettberg, 2012). Therefore, the substitution, reduction or elimination of the number of steps and processes involving manual handling during high risk activities may be a more efficient control measure, in contrast to behavioural interventions such as PPE (ibid.).

The exposure risks to operators arising from the conveyance of urine warrants further study given the findings we gleaned from the environmental data, which show significant levels of faecal contamination on urine containers. As discussed, we found that misuse by toilet users can lead to cross-contamination of faecal matter in the urine diverter portion of the toilet. The toilet operators then faced exposure to faecal matter from the splashback and spillage of urine (which is less viscous than solid waste) during waste collection and conveyance. Although household survey respondents reported relatively few blockages at the time of observation, respondents did refer to occasions of misuse, especially by younger users and the elderly, which would explain the faecal contamination we found on urine collection containers. Notably, previous research has proven inconclusive on the role of urine as a transmission pathway for faecal pathogens. A study by Bischel and colleagues (2015) found 100 per cent of urine samples collected from urine diversion sanitation systems had diarrhoeal bacteria representing a wide spectrum of faecal pathogens (Bischel et al., 2015), whereas a study by Makaya and colleagues (2015) found 100 per cent of urine 
samples negative for rotavirus (RoV) and norovirus (NoV) in a similar study (Makaya et al., 2015). The likelihood of faeces-to-urine cross-contamination, as well as the role of causal mechanisms and controls, are therefore areas of research that demand further exploration. Our data, however, does indicate that cross-contamination of faecal matter into urine collection containers may represent a transmission pathway for faecal pathogens necessitating new and/or improved control measures.

\section{Risk factors}

In the following section, we discuss how the results derived from the case study underscore how exposure risks cannot be controlled effectively by focusing solely on linear causal chains. Instead, a true deconstruction of exposure risks must acknowledge the presence of the multiple, inter-related causal mechanisms and risk factors illustrated in Figure 1, which is supported by the results of the hazard analysis. Firstly, we consider how exposure is driven by equipment and infrastructure design, raw materials selection, and maintenance, which is an idea reflected in the principle of 'safety guided design' popular in the field of systems engineering (Leveson, 2012). For example, interview data from the case study refers to the benefits of child-adapted seats that encourage the correct use of the toilet, while the physical integrity, size, and condition of equipment influences the frequency and severity of spillages during transportation. Previous risk assessments have also pointed to the selection of surface materials as a factor relevant to surface contamination and recommended pre-fabricated plastics and non-porous concrete as materials that enhance the ease of effective cleaning and reduce the risk of contamination.

Secondly, we acknowledge that behavioural factors are fundamental to risk management in sanitation. During interviews, operators referred to the effectiveness of pre-employment and regular training, which they indicated imparted a keen sense of risk awareness. This improved perception of risk, in turn, led to positive behavioural practices, such as compliance with safety protocols, which lowered exposure risks. We therefore consider that the absence of hand hygiene habits referred to in users' KIIs may have resulted from lapses or memory failures not controlled through automation of preventive actions (Hurst, 1998). The implication is that employing successful behaviour change strategies focusing on habit formation regarding hand hygiene may be beneficial in ensuring effective control measures to address both users and occupational exposure risk in this scenario. Proposed interventions may utilize formal behavioural analysis techniques, such as those proposed by Contzen and Mosler (2015) to isolate factors steering desired behaviours and are then linked to specific behavioural interventions (Contzen and Mosler, 2015). To improve specific habitual behaviours, techniques are employed that focus on changing specific factors related to self-regulation. For example, correct personal hand hygiene is enforced by techniques that prompt (self)-monitoring of behaviour; for example, encouraging users to record their hand washing frequency using sticker charts (for children) or activity diaries (for adults) is a proven behavioural intervention. Providing feedback on a persons' handwashing behaviours may also stimulate desired behaviours, or techniques which encourage the user 
to evaluate their own behaviour in relation to a set goal are all recommended by Contzen and Mosler to support desired behaviour changes (Contzen and Mosler, 2015.). For employees, pre-system checklists and safety checks, which encourages habit formation and ensures operator compliance with a range of control measures including PPE, prior to specific operations or activities, is commonplace in sectors contending with high risk operations. Such checklists may be operated via smartphones and monitored in real time, or paper-based.

We also found age to be a contributing behavioural factor in exposure risk. Firstly, toilet misuse is more likely in younger users who demonstrated less familiarity with how to properly operate the toilet, as well as differences in anatomy that could potentially increase their vulnerability to exposure (e.g. falling into the toilet) (Moya et al., 2004). Secondly, children under five have far higher rates of hand-tomouth contact events compared with adults; exposure to faecal pathogens from hand contamination can account for 97-98 per cent of the total faecal matter a child under five ingests in a day (Mattioli et al., 2013; Pickering et al., 2012). Finally, we identified broader socio-economic factors influencing individual anal cleansing behaviours, supported by previous ethnographic research (McMahon et al., 2011) and noted the heightened risks from exposure experienced by especially vulnerable children (e.g. those in low income households) (Rheingans et al., 2014).

A third driver of exposure risk was tangibly represented by a positive safety culture (Hurst, 1998), as reflected in the interviews we conducted with frontline staff and field managers who seemed highly aware of and proactive about potential health risks. Specifically, we observed how front-line staff would consistently bring risks to the attention of management and advocate for methods of improving health and safety across the organization. At the management level, we observed field managers demonstrating a proactive attitude towards risk management through their distribution of health and safety manuals to staff and commitment to ensuring staff receive relevant vaccinations to reduce postexposure vulnerability. We argue that the collaboration between and procedures separately undertaken by front-line staff and field managers for this study are itself an embodiment of a positive safety culture.

Finally, we found that the physical characteristics of the external environment are a fourth factor influencing exposure risk. Seasonal or broader environmental factors are acknowledged to influence level of diseases risk in the ways specific pathways may be affected (Maponga et al., 2013). In this context, the in-depth interviews uncovered how outbreaks of diarrhoeal diseases were perceived to affect the severity of the exposure incident and subsequent health consequences depending on the type and number of disease agents. Our study has uncovered how flooding or other extreme weather events can increase the risk of poor performance of soakaway or drainage units, encouraging environmental contamination of groundwater. Seasonal rain effects were also found to compromise transportation conditions given the absence of tarmac roads and can increase associated exposure risks such as spillage during transportation. Preventive actions including practising emergency scenarios or developing emergency preparedness plans are important risk control strategies. 


\section{Conclusion}

In conclusion, the hazard analysis lays out the key exposure risks that arose during the use and operation of CBS, in particular the potential role of fomites in pathogen transmission. There are no previous studies of which we are aware that examine in comparable detail the risks faced by CBS operators, specifically, during collection and conveyance activities. The risk assessment in the case study draws out the complex and multi-dimensional nature of exposure which is moderated by the specific technical, behavioural, system safety culture, and environmental factors. We believe that the CCPs, when combined with relevant control measures, are able to reduce or prevent exposure risks. However, it is important to keep in mind that our analysis is based on a case study, performed in June 2016, and the results are liable to date quickly given the advancements in this sector. The case study was selected as it represented one of the leading CBS service providers using state of the art and innovative CBS processing and treatment modalities. However, further work is required to update the findings. In the meantime, the CCPs identified and methodological approach presented provide an entry point and tools to adopt for performing future risk assessments in CBS.

\section{Acknowledgment}

The authors acknowledge support from the Impact Scheme Research Studentship UCL REF: 000024303.

\section{References}

Abad, F.X., Villena, C., Guix, S., Caballero, S., Pinto, R.M. and Bosch, A. (2001) 'Potential role of fomites in the vesicular transmission of human astroviruses', Applied and Environmental Microbiology 67(9): 3904-7 <http://dx.doi.org/10.1128/AEM.67.9.3904-3907>.

Ajzen, I. (1985) 'From intentions to actions: a theory of planned behavior', in J. Kuhl and J. Beckmann (eds), Action Control: From Cognition to Behaviour, Berlin: Springer-Verlag.

Antwi-Agyei, P., Peasey, A., Biran, A., Bruce, J. and Ensink, J. (2016) 'Risk perceptions of wastewater use for urban agriculture in Accra, Ghana', PloS One 11(3): e0150603.

Bain, R., Cronk, R., Hossain, R., Bonjour, S., Onda, K., Wright, J., Yang, H. (2014) 'Global assessment of exposure to faecal contamination through drinking water based on a systematic review', Tropical Medicine \& International Health: TM \& IH 19(8): 917-27.

Baker, K.K., O’Reilly, C.E., Levine, M.M., Kotloff, K.L., Nataro, J.P., Ayers, T.L., Farag, T.H. (2016) 'Sanitation and hygiene-specific risk factors for moderate-to-severe diarrhea in young children in the Global Enteric Multicenter Study, 2007-2011: case-control study', PLoS Medicine 13(5): 2007-11 <http://dx.doi.org/10.1371/journal.pmed.1002010>.

Barker, J. and Bloomfield, S.F. (2000) 'Survival of Salmonella in bathrooms and toilets in domestic homes following salmonellosis', Journal of Applied Microbiology 89(1): 137-44 $<$ http://dx.doi.org/10.1046/j.1365-2672.2000.01091.x>.

Berner, C., Woods, E. and Foote, A. (2015) 'Waste transformation, not waste treatment: understanding the value of poop in Sanivation's waste processing model for cities', in Faecal Sludge Management (FSM) 4 Conference Proceedings - Case Study Abstracts, pp. 3-5. 
Bischel, H.N., Özel Duygan, B.D., Strande, L., McArdell, C.S., Udert, K.M. and Kohn, T. (2015) 'Pathogens and pharmaceuticals in source-separated urine in eThekwini, South Africa', Water Research 85: 57-65 <http://dx.doi.org/10.1016/j.watres.2015.08.022>.

Bleck, D. and Wettberg, W. (2012) 'Waste collection in developing countries: tackling occupational safety and health hazards at their source', Waste Management 32(11): 2009-17 $<$ http://dx.doi.org/10.1016/j.wasman.2012.03.025>.

Broomfield, M., Davies, J., Furmston, P., Levy, L., Pollard, S.J.T. and Smith, R. (2010) Exposure Assessment of Landfill Sites Volume 1 : Main Report, London, UK: Environment Agency.

Brown, J., Cumming, O., Bartram, J., Cairncross, S., Ensink, J., Holcomb, D. and Knee, J. (2015) 'A controlled, before-and-after trial of an urban sanitation intervention to reduce enteric infections in children: research protocol for the Maputo Sanitation (MapSan) study, Mozambique', BMJ Open 5(6): e008215.

Buckley, C.A., Foxon, K.M., Hawksworth, D.J., Archer, C., Pillay, S., Appleton, C., Smith, M. and Rodda, N. (2008) Research into UD/VIDP (Urine Diversion Ventilated Improved Double Pit) Toilets: Prevalence and Die-off of Ascaris Ova in Urine Diversion Waste, South Africa: Water Research Commission.

Burgess, T. (2016) Overflowing Cities: The State of the World's Toilets 2016, London: WaterAid.

Buttner, M.P. and Stetzenbach, L.D. (1993) Monitoring airborne fungal spores in an experimental indoor environment to evaluate sampling methods and the effects of human activity on air sampling', Applied and Environmental Microbiology 59(1): 219-26.

Cairncross, S., Hunt, C., Boisson, S., Bostoen, K., Curtis, V., Fung, I.C.H. and Schmidt, W.P. (2010) 'Water, sanitation and hygiene for the prevention of diarrhoea', International Journal of Epidemiology 39(Suppl. 1): 193-205 <http://dx.doi.org/10.1093/ije/dyq035>.

Campos, L.C., Ross, P., Nasir, Z.A., Taylor, H. and Parkinson, J. (2015) 'Development and application of a methodology to assess sanitary risks in Maputo, Mozambique', Environment and Urbanization 27(2): 371-88 <http://dx.doi.org/10.1177/0956247815595784>.

Carrington, E.-G. (2001) Evaluation of Sludge Treatments for Pathogen Reduction [pdf], Luxembourg: European Commission <http://ec.europa.eu/environment/archives/waste/ sludge/pdf/sludge_eval.pdf> [accessed 27 September 2018].

Contzen, N. and Mosler, H.J. (2015) Methodological Fact Sheet 1: The Risks, Attitudes, Norms, Abilities, and Self-regulation (RANAS) Approach to Systematic Behavior Change, Dübendorf, Switzerland: Eawag, Swiss Federal Institute of Aquatic Science and Technology.

Curtis, V., Cairncross, S. and Yonli, R. (2000) 'Domestic hygiene and diarrhoea', Tropical Medicine and International Health 5(1): 22-32 <http://dx.doi.org/10.1046/j.1365-3156.2000.00512.x>.

Curtis, V., de Barra, M. and Aunger, R. (2011) 'Disgust as an adaptive system for disease avoidance behaviour', Philosophical Transactions of the Royal Society of London. Series B, Biological Sciences 366(1563): 389-401 <http://dx.doi.org/10.1098/rstb.2010.0117>.

Darout, I.A., Astrom, A.N. and Skaug, N. (2005) 'Knowledge and behaviour related to oral health among secondary school students in Khartoum Province, Sudan', International Dental Journal 55(4): 224-30.

Devamani, C., Norman, G. and Schmidt, W.-P. (2014) 'A simple microbiological tool to evaluate the effect of environmental health interventions on hand contamination', International Journal of Environmental Research and Public Health 11(11): 11846-59.

Devine, J. and Devine, J. (2009) Introducing SaniFOAM : A Framework to Analyze Sanitation Behaviors to Design Effective Sanitation Programs [pdf], Water and Sanitation Program Working 
Paper <http://documents.worldbank.org/curated/en/272351468334778050/pdf/722050WSP0 Box30PUBLIC00GSP0sanifoam.pdf> [accessed 26 September 2018].

Drechsel, P., Amoah, P., Löfman, O., Heistad, A., Fodge, M., Jenssen, P. and Stenström, T.A. (2008) 'Quantitative microbial risk assessment of wastewater and faecal sludge reuse in Ghana', in J. Hazel (ed.), Proceedings of the 33rd WEDC International Conference on Access to Sanitation and Safe Water: Global Partnerships and Local Actions, Accra, Ghana, 7-11 April 2008, pp. 90-7, Leicestershire, UK: Water, Engineering and Development Centre (WEDC).

du Preez, M., Conroy, R.M., Ligondo, S., Hennessy, J., Elmore-Meegan, M., Soita, A. and McGuigan, K.G. (2011) 'Randomized intervention study of solar disinfection of drinking water in the prevention of dysentery in Kenyan children aged under 5 years', Environmental Science \& Technology 45: 9315-23 <http://dx.doi.org/10.1021/es2018835>.

Edmunds, K.L., Abd Elrahman, S., Bell, D.J., Brainard, J., Dervisevic, S., Fedha, T.P. and Few, R. (2016) 'Recommendations for dealing with waste contaminated with Ebola virus: a hazard analysis of critical control points approach', Bulletin of the World Health Organization (94): 424-32 <http://dx.doi.org/10.2471/BLT.15.163931>.

Emch, M. (1999) 'Diarrheal disease risk in Matlab, Bangladesh', Social Science and Medicine 49(4): 519-30 <http://dx.doi.org/10.1016/S0277-9536(99)00146-X>.

Enger, K.S., Nelson, K.L., Rose, J.B. and Eisenberg, J.N.S. (2013) 'The joint effects of efficacy and compliance: a study of household water treatment effectiveness against childhood diarrhea', Water Research 47(3): 1181-90 <http://dx.doi.org/10.1016/j.watres.2012.11.034>.

Exley, J.L.R., Liseka, B., Cumming, O. and Ensink, J.H.J. (2015) 'The sanitation ladder, what constitutes an improved form of sanitation?' Environmental Science and Technology 49(2): 1086-94 <http://dx.doi.org/10.1021/es503945x>.

Feacham, R., Bradley, D.H., Garelick, H. and Mara, D.D. (eds) (1983) Sanitation and Disease: Health Aspects of Excreta and Wastewater Management, Washington, DC: World Bank.

Forsythe, S.J. (2010) The Microbiology of Safe Food, 2nd edn, London: Blackwell Publishing Ltd.

Graf, J., Meierhofer, R., Wegelin, M. and Mosler, H.J. (2008) 'Water disinfection and hygiene behaviour in an urban slum in Kenya: impact on childhood diarrhoea and influence of beliefs', International Journal of Environmental Health Research 18(5): 335-55.

Haagsma, J., Tariq, L., Heederik, D.J. and Havelaar, A.H. (2012) 'Infectious disease risks associated with occupational exposure: a systematic review of the literature', Occupational and Environmental Medicine 69(2): 140-6 <http://dx.doi.org/10.1136/oemed-2011-100068>.

Haas, C. (2014) 'QMRAwiki dose response' [online], <http://qmrawiki.canr.msu.edu/index. php/Dose_Response> [accessed 26 September 2018].

Höglund, C. (2001) Evaluation of Microbial Health Risks Associated with the Reuse of SourceSeparated Human Urine, doctoral thesis, Royal Institute of Technology (KTH) Department of Biotechnology, Applied Microbiology Swedish Institute for Infectious Disease Control (SMI) Department of Water and Environmental Microbiology, Stockholm.

Humphrey, J.H. (2009) 'Child undernutrition, tropical enteropathy, toilets, and handwashing', The Lancet 374(9694): 1032-5 <http://dx.doi.org/10.1016/S0140-6736(09)60950-8>.

Hurst, N.W. (1998) Risk Assessment The Human Dimensions, United Kingdom: Royal Society of Chemistry Publishing.

Julian, T.R. (2016) 'Environmental transmission of diarrheal pathogens in low and middle income countries', Environmental Science: Processes \& Impacts 18: 944-55 <http://dx.doi.org/10.1039/ C6EM00222F>. 
Julian, T.R., Leckie, J.O. and Boehm, A.B. (2010) 'Virus transfer between fingerpads and fomites', Journal of Applied Microbiology 109(6): 1868-74 <http://dx.doi.org/10.1111/ j.1365-2672.2010.04814.x>.

Katukiza, A.Y., Ronteltap, M., van der Steen, P., Foppen, J.W.A. and Lens, P.N.L. (2014) 'Quantification of microbial risks to human health caused by waterborne viruses and bacteria in an urban slum', Journal of Applied Microbiology 116(2): 447-63 <http://dx.doi.org/10.1111/ jam.12368>.

Leveson, N.G. (2011) Engineering a Safer World: Systems Thinking Applied to Safety [pdf] $<$ http://sunnyday.mit.edu/safer-world.pdf > [accessed 27 September 2018].

Leveson, N. (2012) 'Safety-guided design', in Engineering a Safer World: Systems Thinking Applied to Safety, Cambridge, MA: Massachusetts Institute of Technology (MIT) Press.

Lingaas, E. and Fagernes, M. (2009) 'Development of a method to measure bacterial transfer from hands', Journal of Hospital Infection 72(1): 43-9 <http://dx.doi.org/10.1016/j. jhin.2009.01.022>.

Makaya, J.M., Kaplon, J., Fremy, C., Barro, N., Aho, S., Pothier, P., Belliot, G. and Traore, A.S. (2015) 'Norovirus and rotavirus survival in urine collected from a public ecological sanitation system in Ouagadougou, Burkina Faso', Food and Environmental Virology 7(1): 41-8.

Maponga, B.A., Chirundu, D., Gombe, N.T., Tshimanga, M., Shambira, G. and Takundwa, L. (2013) 'Risk factors for contracting watery diarrhoea in Kadoma City, Zimbabwe, 2011: a case control study', BMC Infectious Diseases 13: 567.

Mara, D.D. and Oragui, J. (1985) 'Bacteriological methods for distinguishing between human and animal faecal pollution of water: results of fieldwork in Nigeria and Zimbabwe', Bulletin of the World Health Organization 63(4): 773-83.

Maricou, H., Verstraete, W. and Mesuere, K. (1998) 'Hygienic aspects of biowaste composting: airborne microbial concentrations as a function of feedstock, operation and season', Waste Management \& Research 16(4): 304-11 <http://dx.doi.org/10.1177/07 34242X9801600402>.

Mattioli, M.C.M., Pickering, A.J., Gilsdorf, R.J., Davis, J. and Boehm, A.B. (2013) 'Hands and water as vectors of diarrheal pathogens in Bagamoyo, Tanzania', Environmental Science \& Technology 47(1): 355-63 <http://dx.doi.org/10.1021/es303878d >.

Mattioli, M.C.M., Davis, J. and Boehm, A.B. (2015) 'Hand-to-mouth contacts result in greater ingestion of feces than dietary water consumption in Tanzania: a quantitative fecal exposure assessment model', Environmental Science \& Technology 49(3): 1912-20 <http://dx.doi. org/10.1021/es505555f $>$.

Mayer, J. (1986) 'Ecological associative analysis', in M. Pacione (ed.), Medical Geography: Progress and Prospect, p. 64, London: Croom Helm.

McMahon, S., Caruso, B.A., Obure, A., Okumu, F. and Rheingans, R.D. (2011) 'Anal cleansing practices and faecal contamination: a preliminary investigation of behaviours and conditions in schools in rural Nyanza Province, Kenya', Tropical Medicine and International Health 16(12): 1536-40 <http://dx.doi.org/10.1111/j.1365-3156.2011.02879.x>.

Medland, L., Cotton, A.P. and Scott, R.E. (2015) Understanding and Addressing Vulnerability in the Sanitation Service Chain, SPLASH Urban Sanitation Research Programme Briefing Note 3, Loughborough, UK: Water, Engineering and Development Centre (WEDC).

Michie, S., West, R., Campbell, R., Brown, J. and Gainforth, H. (2014) ABC of Behavior Change Theories, 1st edn, London: Silverback Publishing. 
Mnkeni, P.N.S., Kutu, F.R., Muchaonyerwa, P. and Austin, L.M. (2008) 'Evaluation of human urine as a source of nutrients for selected vegetables and maize under tunnel house conditions in the Eastern Cape, South Africa', Waste Management \& Research: The Journal of the International Solid Wastes and Public Cleansing Association, ISWA 26(2): 132-9.

Moore, G. and Griffith, C. (2007) 'Problems associated with traditional hygiene swabbing: the need for in-house standardization', Journal of Applied Microbiology 103(4): 1090-103 $<$ http://dx.doi.org/10.1111/j.1365-2672.2007.03330.x>.

Mosler, H. (2012a) 'A systematic approach to behavior change interventions for the water and sanitation sector in developing countries: a conceptual model, a review, and a guideline', International Journal of Environmental Health Research 22: 431-49.

Mosler, H. (2012b) 'How to achieve evidence-based behavioural change', Sandec News: 14-5.

Moya, J., Bearer, C.F. and Etzel, R. (2004) 'Various life stages', Pediatrics 113(4): 996-1006 $<$ http://dx.doi.org/10.1542/peds.113.4.S1.996>.

Mwase, I., Mutoro, A., Owino, V., Garcia, A-L. and Wright, C.M. (2016) 'Poor infant feeding practices and high prevalence of malnutrition in urban slum child care centres in Nairobi: a pilot study', Journal of Tropical Pediatrics 62(1): 46-54.

Ngure, F.M., Reid, B.M., Humphrey, J.H., Mbuya, M.N., Pelto, G. and Stoltzfus, R.J. (2014) 'Water, sanitation, and hygiene (WASH), environmental enteropathy, nutrition, and early child development: making the links', Annals of the New York Academy of Sciences 1308(1): 118-28<http://dx.doi.org/10.1111/nyas.12330>.

Nyoka, R., Foote, A.D., Woods, E., Lokey, H., O’Reilly, C.E., Magumba, F., Okello, P., Mintz, E.D., Marano, N. and Morris, J.F. (2017) 'Sanitation practices and perceptions in Kakuma refugee camp, Kenya: comparing the status quo with a novel service-based approach', PLoS ONE 12(7): $1-16<$ http://dx.doi.org/10.1371/journal.pone.0180864>.

O'Keefe, M., Luthi, C., Tumwebaze, I.K. and Tobias, R. (2015) 'Opportunities and limits to market-driven sanitation services: evidence from urban informal settlements in East Africa', Environment and Urbanization 27(2): 421-40<https://doi.org/10.1177\%2F0956247815581758>.

Peasey, A. (2000) 'Health aspects of dry sanitation with waste reuse', Knowledge Creation Diffusion Utilization 324: 48.

PHE (2013) Detection and Enumeration of Bacteria in Swabs and Other Environmental Samples, Microbiology Services Food Water and Environmental Microbiology Standard Method [online], London: Public Health England, Microbiology Services Food, Water \& Environmental Microbiology Methods Working Group <www.hpa.org.uk/ProductsServices/MicrobiologyPathology/Specialist MicrobiologyServices/FoodWaterEnvironmentalMicrobiologyServices/NationalReferenceLab oratoryForFoodMicrobiology/> [accessed 27 September 2018].

Pickering, A.J., Julian, T.R., Marks, S.J., Mattioli, M.C., Boehm, A.B., Schwab, K.J. and Davis, J. (2012) 'Fecal contamination and diarrheal pathogens on surfaces and in soils among Tanzanian households with and without improved sanitation', Environmental Science \& Technology 46(11): 5736-43 <http://dx.doi.org/10.1021/es300022c>.

Prüss-üstün, A., Kay, D., Fewtrell, L. and Bartram, J. (2004) 'Unsafe water, sanitation and hygiene', in M. Ezzati, A.D. Lopez, A. Rodgers, and C.L.J. Murray (eds), Comparative Quantification of Health Risks Global and Regional Burden of Disease Attributable to Selected Major Risk Factors Volume 1, pp. 1321-52, Geneva: WHO.

Rheingans, R., Anderson, J.D., Luyendijk, R. and Cumming, O. (2014) 'Measuring disparities in sanitation access: does the measure matter?' Tropical Medicine \& International Health: TM \& IH 19(1): 2-13. 
Robb, K., Null, C., Teunis, P., Yakubu, H., Armah, G. and Moe, C.L. (2017) 'Assessment of fecal exposure pathways in low-income urban neighborhoods in Accra, Ghana: rationale, design, methods, and key findings of the Sanipath study', American Journal of Tropical Medicine and Hygiene 97(4): 1020-32 <http://dx.doi.org/10.4269/ajtmh.16-0508>.

Rochelle-Newall, E., Huong Nguyen, T.M., Quynh Le, T.P., Sengtaheuanghoung, O. and Ribolzi, O. (2015) 'A short review of fecal indicator bacteria in tropical aquatic ecosystems: knowledge gaps and future directions', Frontiers in Microbiology 6: 308.

Rongo, L.M.B., Barten, F., Msamanga, G.I., Heederik, D. and Dolmans, W.M.V. (2004) 'Occupational exposure and health problems in small-scale industry workers in Dar es Salaam, Tanzania: a situation analysis', Occupational Medicine (Oxford, England) 54(1): 42-6.

Rusin, P., Maxwell, S. and Gerba, C. (2002) 'Comparative surface-to-hand and fingertip-tomouth transfer efficiency of gram-positive bacteria, gram-negative bacteria, and phage', Journal of Applied Microbiology 93(4): 585-92 <http://dx.doi.org/10.1046/j.1365-2672.2002.01734.x>.

Russel, K., Tilmans, S. Kramer, S., Sklar, R., Tillias, D. and Davis, J. (2015) 'User perceptions of and willingness to pay for household container-based sanitation services: experience from Cap Haitien, Haiti', Environment and Urbanization 27(2): 525-40 <http://dx.doi. org/10.1177/0956247815596522>.

Scammel, M.K. (2010) 'Qualitative environmental health research: an analysis of the literature: 1991-2008', Environmental Health Perspectives 118(8): 1146-54.

Scheithauer, S., Häfner, H., Seef, R., Seef, S., Hilgers, R.D. and Lemmen, S. (2016) 'Disinfection of gloves: feasible, but pay attention to the disinfectant/glove combination', Journal of Hospital Infection 94(3): 268-72 <http://dx.doi.org/10.1016/j.jhin.2016.08.007>.

Scott, E., Bloomfield, S.F. and Barlow, C.G. (1982) 'An investigation of microbial contamination in the domestic environment', Journal of Hygiene (Cambridge) 89: 279-93.

Stenström, T.A., Seidu, R., Nelson, E. and Christian, Z. (2011) Microbial Exposure and Health Assessments in Sanitation Technologies and Systems [pdf], Stockholm, Sweden: EcoSanRes Programme, Stockholm Environment Institute <www.ecosanres.org/pdf_files/Microbial_ Exposure_\&_Health_Assessments_in_Sanitation_Technologies_\&_Systems.pdf> [accessed 26 September 2018].

Thomas, E., Andrés, L.A., Borja-Vega, C. and Sturzenegger, G. (2018) Innovations in WASH Impact Measures: Water and Sanitation Measurement Technologies and Practices to Inform the Sustainable Development Goals, Washington, DC: World Bank.

Tilmans, S., Russel, K., Sklar, R., Page, L., Kramer, S. and Davis, J. (2016) 'Container-based sanitation: assessing costs and effectiveness of excreta management in Cap Haitien, Haiti', Environment and Urbanization 27(6), 89-104 <http://dx.doi.org/10.1177/0956247815572746>.

Tschopp, A., Bernard, A., Thommen, A.M., Jeggli, S., Dumont, X., Oppliger, A. and Hotz, P. (2011) 'Exposure to bioaerosols, respiratory health and lung-specific proteins: a prospective study in garbage and wastewater workers', Occupational and Environmental Medicine 68(11): 856-9 <http://dx.doi.org/10.1136/oem.2010.060178>.

Turner, S., Lines, S., Chen, Y., Hussey, L. and Agius, R. (2005) 'Work-related infectious disease reported to the Occupational Disease Intelligence Network and The Health and Occupation Reporting network in the UK (2000-2003)', Occupational Medicine 55(4): 275-81 <http://dx.doi. org/10.1093/occmed/kqi109>.

Walser, S.M., Gerstner, D.G., Brenner, B., Bünger, J., Eikmann, T., Janssen, B., Kolb, S., Kolk, A., Nowak, D., Raulf, M., Sagunski, H., Sedlmaier, N., Suchenwirth, R., Wiesmüller, G., Wollin, K.M., Tesseraux, I. and Herr, C.E.W. (2015) 'Evaluation of exposure-response relationships for health 
effects of microbial bioaerosols: a systematic review', International Journal of Hygiene and Environmental Health 218(7): 577-89 <http://dx.doi.org/10.1016/j.ijheh.2015.07.004>.

Wang, Y., Moe, C.L., Null, C., Raj, S.J., Baker, K.K., Robb, K.A. and Yakubu, H. (2017) 'Multipathway quantitative assessment of exposure to fecal contamination for young children in low-income urban environments in Accra, Ghana: the Sanipath analytical approach', American Journal of Tropical Medicine and Hygiene 97(4): 1009-19 <http://dx.doi.org/10.4269/ ajtmh.16-0408>.

Westrell, T. (2004) Microbial Risk Assessment and its Implications for Risk Management in Urban Water Systems, doctoral thesis, Linköping University, The Tema Institute, Department of Water and Environmental Studies, Linköping: Linköping University Electronic Press.

WHO (2003) Annex 7 Application of Hazard Analysis and Critical Control Point (HACCP) Methodology to Pharmaceuticals, WHO Technical Report Series, No. 908, 2003 Annex, pp. 99-112, Geneva: WHO.

WHO (2016) Sanitation Safety Planning, Geneva: WHO.

WHO (2017) Progress on Drinking Water, Sanitation and Hygiene, Geneva: WHO.

Worrell, C.M., Wiegand, R.E., Davis, S.M., Odero, K.O., Blackstock, A., Cuéllar, V.M., Njenga, S.M., Montgomery, J.M., Roy, S.L. and Fox, L.M. (2016) 'A cross-sectional study of water, sanitation, and hygiene-related risk factors for soil-transmitted helminth infection in urban school- and preschool-aged children in Kibera, Nairobi', Plos One 11(3): e0150744 $<$ http://dx.doi.org/10.1371/journal.pone.0150744>.

WSUP/EY (2017) The World Can't Wait for Sewers [pdf], Water \& Sanitation for the Urban Poor and Ernst and Young <www.ey.com/Publication/vwLUAssets/ey-the-world-cant-wait-forsewers/\$FILE/ey-the-world-cant-wait-for-sewers.pdf> [accessed 27 September 2018]. 